\title{
On the Estimation of Parameters and Best Model Fits of Log Linear Model for Contingency Table
}

\author{
Cecilia N. Okoli1 ${ }^{*}$, Sidney I. Onyeagu ${ }^{2}$, George A. Osuji ${ }^{2}$ \\ ${ }^{1}$ Department of Statistics, Anambra State University, Uli, Nigeria \\ ${ }^{2}$ Department of Statistics, Nnamdi Azikiwe University, Awka, Nigeria \\ Email: ${ }^{*}$ cecilia.okoli@yahoo.com, ${ }^{*}$ donfadino@yahoo.com
}

Received 18 November 2014; revised 25 December 2014; accepted 10 January 2015

Copyright $(0) 2015$ by authors and OALib.

This work is licensed under the Creative Commons Attribution International License (CC BY). http://creativecommons.org/licenses/by/4.0/

(c) (i) Open Access

\begin{abstract}
In this paper, we proposed the generalized method and algorithms developed for estimation of parameters and best model fits of log linear model for $n$-dimensional contingency table. For purpose of this work, the method was used to provide parameter estimates of log-linear model for three-dimensional contingency table. In estimating parameter estimates and best model fit, computer programs in $\mathbf{R}$ were developed for the implementation of the algorithms. The iterative proportional fitting procedure was used to find the parameter estimates and goodness of fits of the log linear model. Akaike information criteria (AIC) and Bayesian information criteria (BIC) were used to check the adequacy of the model of the best fit. Secondary data were used for illustration and the result obtained showed that the best model fit for three-dimensional contingency table had a gene-rating class: [CA, $\mathrm{AB}]$. This showed that the best model fit had sufficient evidence to fit the data without loss of information. This model also revealed that breed was independent of chick loss given age. The best model in harmony with the hierarchy principle is
\end{abstract}

$\operatorname{Logm}_{i j k}=\mu+\mu_{C(i)}+\mu_{A(j)}+\mu_{B(k)}+\mu_{C A(j)}+\mu_{A B(j k)}$.

\section{Keywords}

Hierarchical Log Linear Models, Categorical Data, Contingency Table, Likelihood Ratio Test Statistic, AIC, BIC, Interaction

Subject Areas: Mathematical Analysis, Mathematical Statistics

\section{Introduction}

Contingency tables [1] are formed when a population is cross-classified according to a series of categories (or

*Corresponding author.

How to cite this paper: Okoli, C.N., Onyeagu, S.I. and Osuji, G.A. (2015) On the Estimation of Parameters and Best Model Fits of Log Linear Model for Contingency Table. Open Access Library Journal, 2: e1189.

http://dx.doi.org/10.4236/oalib.1101189 
factors). Additionally, $n$-contingency table is a contingency table created by cross-classification of more than two categorical variables. A categorical variable is one for which the measurement scale consists of a set of categories. Categorical data are data consisting of counts of observation falling in different categories. Categorical data in contingency tables are collected in many investigations. In order to understand the type of structures in such data appropriate log linear models are fitted. Log linear models are used to model the observed cell count where the log of expected cell count is proportional to linear combination involving number of model parameters. Log-linear models are used to determine whether there are any significant relationships in $n$-way contingency tables that have three or more categorical variables and/or to determine if the distribution of the counts among the cells of a table can be explained by a simpler, underlying structure (restricted model). It is a specialized case of generalized linear model for Poisson distributed data and is more commonly used for analyzing $n$-dimensional contingency tables that involve more than two variables, though it can also be used to analyze two-way contingency table [2]. A saturated model imposes no constraints on the data and always reproduces the observed counts. The parsimonious model in log linear model analysis is an incomplete model that achieves satisfactory level of goodness of fit. The log linear model is called a hierarchical model; whenever a higher-order interactions is included, lower-order interactions composed of these variables must also be included. The reason for including lower-order terms is that the statistical significance and practical interpretation of higher-order terms depend on how the variables are coded. This is undesirable, but with hierarchical models, the same results are obtained, irrespective of how the variables are coded [1]. Akaike information criteria and Bayesian information criteria are used for checking adequacy of model fit. The comparison of the model using information criteria can be viewed as equivalent to likelihood ratio test and understanding the differences among criteria may make it easier to compare the results and use them to make informed decisions [3]. The aim of this research work is to use a generalized method for estimation of parameters and algorithms developed implemented in $\mathrm{R}$ computer programs for estimating the parameter estimates and best model fit of log linear model for threedimensional contingency table.

\section{Review of Related Literature}

[4] presented a survey on the theory of multidimensional contingency tables and showed that estimation and performance of asymptotic as well as exact tests are simple if only the decomposable models are considered.

[5] emphasized on log linear analysis of cross classification tables with ordinal variables. He also compared chi square of independence with log linear model of independence. The result showed that the log linear model is more adequate for the test.

[6] applied log linear model on categorical data cross-tabulated on contingency table and the results was shown for the hypothesis testing and model building for the categorical data.

[7] applied hierarchical log linear analysis method to occupational fatalities in the underground coal mines of Turkish Hardcoal Enterprises. The accidents records were evaluated and the main factors affecting the accidents were defined. The results found showed that the mostly affected job group by the fatality accidents was the production workers and these workers were mostly exposed to roof collapses and methane explosions.

[8] presented a modeling effort in estimating the relationships between driver's fault and carelessness and the traffic variables. The result of the analysis showed that the best fit model regarding these variables was loglinear model. Also, the associations of the factors with the accident severity and the contributions of the various factors and interactions between these variables were assessed. The obtained results provided valuable information in regard to preventing undesired consequences of traffic accidents.

[9] described the log linear model as a frame work for analyzing effects in contingency tables. That is, tables of frequencies formed by two or three variables of classification and he considered variables to have nominal categories. He further considered two test procedures via maximum likelihood estimation of expected cell frequencies and associated chi-square tests and chi-square tests based on logarithm of adjusted cell frequencies for testing for parameter of the model.

\section{Methodology}

\subsection{Data Collection}

Data for 510 chickens on breed, age and chick loss were collected from poultry record book of Sambo feeds, Awka, Nigeria. The breed, age, and chick loss were classified into two, three and two categories of levels respectively. 


\subsection{Proposed Generalized Method}

For any $|[j]|=t(t \neq 0)$ and $n<\infty(n \in N)$, we define

$$
\mu_{\left\{j_{t}\right\}\left(i_{j_{t}}\right)}:=\log \left\{\frac{\sum_{i_{j_{q}} / i_{j_{t}}} n_{\left(i_{j_{t}}++\right)}}{i_{j_{q}} / i_{j_{t}}}\right\}-\sum_{r=0}^{t-1} \sum_{\left\{j_{s}\right\} \in \mathbb{P}\left(\left\{j_{t}\right\}:\left\{j_{s}\right\} \mid=r\right)} \mu_{\left\{j_{s}\right\}\left(i_{j_{s}}\right)} ; \quad\left\{j_{t}\right\} \in P\left([n]:\left|\left\{j_{t}\right\}\right|=t\right), \quad t=1,2, \cdots, n
$$

where $[n]=\{1,2, \cdots, n\}, P([n])$ is the power set of $[n]$.

$[\underline{j}] \mid$ is the level of interaction/cardinality of the set/length of element in the set. $j$ is a member of collections of sequence $[n]$ and $\log \left(m_{i[n]}\right)=\sum_{\{j\} \in P([n]: 0 \leq\{j\}\} \leq n)} \mu_{\{j\}\}\left(i_{j}\right)}$.

For $n=3$ the saturated log linear model for 3-diimensional contingency table and its parameters effects is given by

$$
\log m_{i_{1} i_{2} i_{3}}=\mu+\mu_{1\left(i_{1}\right)}+\mu_{2\left(i_{2}\right)}+\mu_{3\left(i_{3}\right)}++\mu_{12\left(i_{1} i_{2}\right)}+\mu_{13\left(i_{1} i_{3}\right)}+\mu_{23\left(i_{2} i_{3}\right)}+\mu_{123\left(i_{1} i_{2} i_{3}\right)} .
$$

Conventionally, we take $\mu \phi(\phi)=\mu$ and

$$
\begin{aligned}
& |[\underline{J}]|=0(\text { i.e }[\underline{J}]=\phi) \text {; } \\
& \hat{\mu}=\log \left(\frac{\sum_{i_{1} i_{2} i_{3}} n_{i_{1} i_{2} i_{3}}}{I_{i_{1}} I_{i_{2}} I_{i_{3}}}\right) \\
& |[\underline{J}]|=1 \text {; } \\
& \hat{\mu}_{[1]\left(i_{1}\right)}=\log \left(\frac{\sum_{i_{2} i_{3}} n_{\left(i_{1},+\right)}}{I_{i_{2}} I_{i_{3}}}\right)-\hat{\mu} \\
& \hat{\mu}_{[2]\left(i_{2}\right)}=\log \left(\frac{\sum_{i_{i_{i}} n_{\left(i_{2},+\right)}}}{I_{i_{1}} I_{i_{3}}}\right)-\hat{\mu} \\
& \hat{\mu}_{[3]\left(i_{3}\right)}=\log \left(\frac{\sum_{i_{i_{2}}} n_{\left(i_{3},+\right)}}{I_{i_{1}} I_{i_{2}}}\right)-\hat{\mu} \\
& |[\underline{J}]|=2 \\
& \hat{\mu}_{[12]\left(i_{1} i_{2}\right)}=\log \left(\frac{\sum_{i_{3}} n_{\left(i_{1}, i_{2},+\right)}}{I_{i_{3}}}\right)-\hat{\mu}-\hat{\mu}_{[1]\left(i_{1}\right)}-\hat{\mu}_{[2]\left[\left(i_{2}\right)\right.} \\
& \hat{\mu}_{[13]\left(i_{1} i_{3}\right)}=\log \left(\frac{\sum_{i_{2}} n_{\left(i_{1 i^{3}},+\right)}}{I_{i_{2}}}\right)-\hat{\mu}-\hat{\mu}_{[1]\left(i_{1}\right)}-\hat{\mu}_{[3]\left(i_{3}\right)} \\
& \hat{\mu}_{[23]\left(i_{2} i_{3}\right)}=\log \left(\frac{\sum_{i_{1}} n_{\left(i_{2} i_{3},+\right)}}{I_{i_{1}}}\right)-\hat{\mu}-\hat{\mu}_{[2]\left(i_{2}\right)}-\hat{\mu}_{[3]\left(i_{3}\right)} .
\end{aligned}
$$




\subsection{Iterative Proportional Fitting Procedure}

The iterative proportional fitting (IPF) in [10] is used to estimate model parameters and best model fit of log linear model. This is to ensure that the expected values are obtained iteratively for model whose expected values are not directly obtainable from marginal totals of observed values. For example if we consider 3-dimensional table, for model of No-three factor interaction or pair-wise association [12] [13] [23], IPF algorithm for finding expected frequencies $\left(m_{i j k}\right)$.

The $\hat{m}_{i j k}$ 's of the model is characterized by fitted margins $\hat{m}_{i j .}=n_{i j .}, \quad \hat{m}_{i . k}=n_{i . k}, \quad \hat{m}_{. j k}=n_{. j k}$.

The procedure assumes initial value $\hat{m}_{i j k}(0)=1$, the modifications are

$$
\begin{gathered}
\hat{m}_{i j k}(1)=\frac{\hat{m}_{i j k}(0) n_{i j .}}{\hat{m}_{i j .}(0)} \\
\hat{m}_{i j k}(2)=\frac{\hat{m}_{i j k}(1) n_{i . k}}{\hat{m}_{i . k}(1)} \\
\hat{m}_{i j k}(3)=\frac{\hat{m}_{i j k}(2) n_{. j k}}{\hat{m}_{. j k}(2)} .
\end{gathered}
$$

The second cycle is of the same form as the first cycle above but uses updated estimates

$$
\begin{gathered}
\hat{m}_{i j k}(4)=\frac{\hat{m}_{i j k}(3) n_{i j .}}{\hat{m}_{i j .}(3)} \\
\hat{m}_{i j k}(5)=\frac{\hat{m}_{i j k}(4) n_{i, k}}{\hat{m}_{i, k}(4)} \\
\hat{m}_{i j k}(6)=\frac{\hat{m}_{i j k}(5) n_{i, k}}{\hat{m}_{i, k}(5)} .
\end{gathered}
$$

The steps are repeated until convergence to desired accuracy is attained.

\subsection{Comparison of Models and Goodness of Fit Measure}

The goodness of fit can be assessed by a number of statistics. The statistics include Pearson chi-square test statistic due to [11]; likelihood ratio statistic $\left(G^{2}\right)$ due to [12]; Modified log likelihood ratio due to [13]; Neyman modified chi-square due to [14]; Modified Freeman Tukey due to [15]. Comparative studies have suggested preference for $G^{2}$ Statistic over others due to decomposability into small components and simplicity when comparing two models [16].

$G^{2}$ statistic is given as

$$
G^{2}=2 \sum_{i j k} n_{i j k} \ln \left(\frac{n_{i j k}}{m_{i j k}}\right)
$$

where $G^{2}$ is chi-square distributed with degree of freedom (d.f) equal to:

d.f $=$ number of cells in the table-number of independent parameters estimated.

\subsection{Information Theory Measures of Model Fit}

Information criteria should be considered also for testing the adequacy of the model fit. Akaike information criteria [3] are given as:

$$
\mathrm{AIC}=G^{2}-2 \text { d.f. }
$$

Another information criteria is Bayesian information [17] is given as

$$
\mathrm{BIC}=G^{2}-\ln n \text { d.f }
$$


where $n$ and d.f is the total sample size and degree of freedom respectively.

\section{Analysis and Results}

Implementation of Algorithms in $\boldsymbol{r}$ for Estimating Parameter Estimates, Expected Values and Goodness of Fit of Log Linear Model for 3-Dimensional Contingency Table

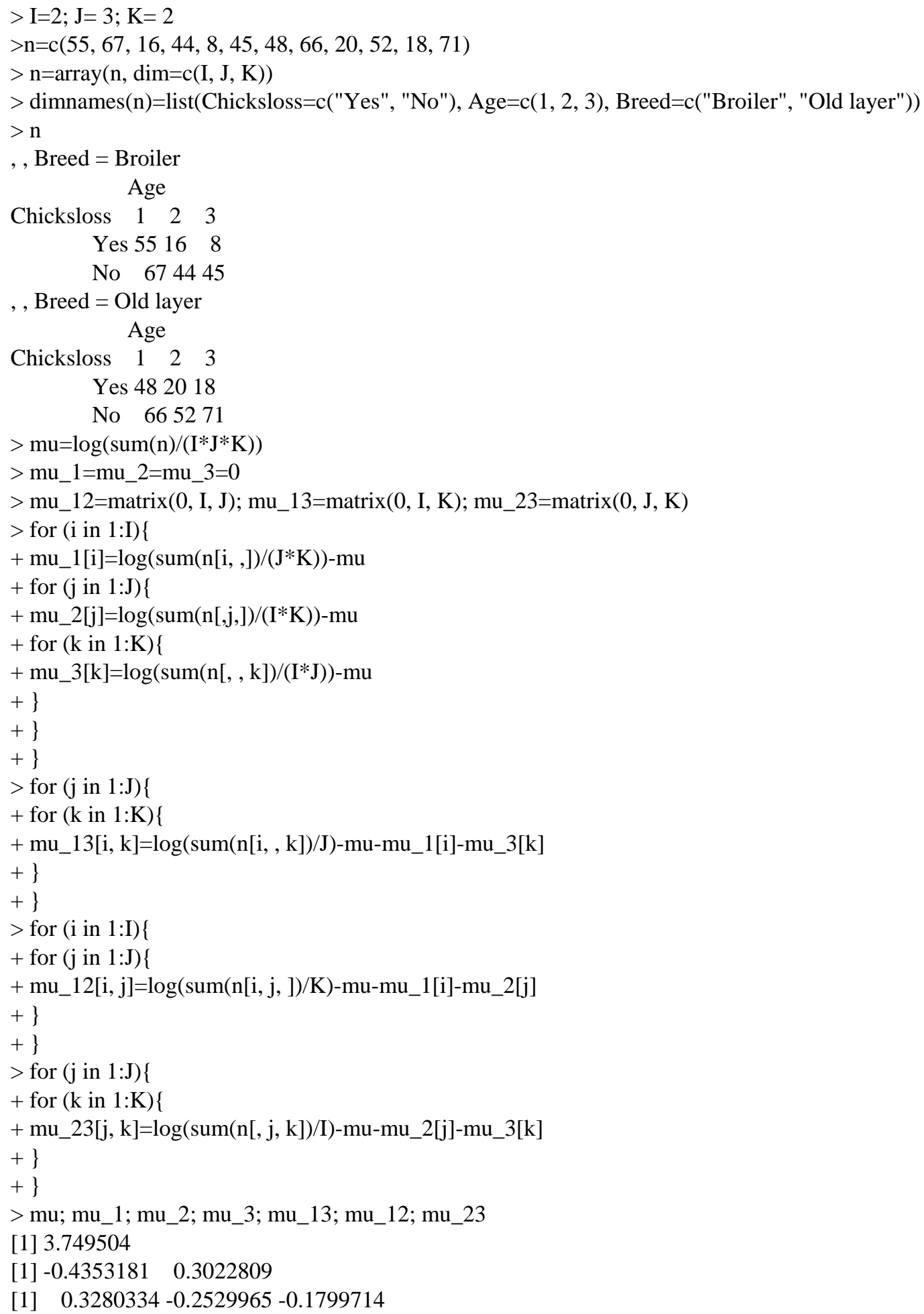


[1] $-0.08167803 \quad 0.07550755$

$[, 1] \quad[, 2]$

[1,] $\quad 0.00000000 .00000000$

[2,] -0.01886320 .01584223$

[,1] [,2] [,3]

[1,] $\quad 0.2993624-0.17081773-0.5692653$

[2,] $-0.1826164 \quad 0.07241258 \quad 0.1886294$

[,1] [,2]

[1,] $0.11501445-0.10999373$

[2,] $-0.01363215 \quad 0.01150382$

[3,] $-0.21070993 \quad 0.15044894$

$>\mathrm{m} \_1=\mathrm{m} \_2=\mathrm{m} \_3=\mathrm{m} \_4=\operatorname{array}(0, \operatorname{dim}=\mathrm{c}(\mathrm{I}, \mathrm{J}, \mathrm{K}))$

$>$ for(i in $1: \mathrm{I})\{$

+ for $(\mathrm{j}$ in $1: J)\{$

+ for $(\mathrm{k}$ in $1: \mathrm{K})\{$

$+\mathrm{m} \_1[\mathrm{i}, \mathrm{j}, \mathrm{k}]=\exp \left(\mathrm{mu}+\mathrm{mu} \_1[\mathrm{i}]+\mathrm{mu} \_2[\mathrm{j}]+\mathrm{mu} \_3[\mathrm{k}]\right)$

$+\mathrm{m} \_2[\mathrm{i}, \mathrm{j}, \mathrm{k}]=\exp \left(\mathrm{mu}+\mathrm{mu} \_1[\mathrm{i}]+\mathrm{mu}_{2} 2[\mathrm{j}]+\mathrm{mu}_{-} 3[\mathrm{k}]+\mathrm{mu} \_13[\mathrm{i}, \mathrm{k}]\right)$

$+\mathrm{m} \_3[\mathrm{i}, \mathrm{j}, \mathrm{k}]=\exp \left(\mathrm{mu}+\mathrm{mu} \_1[\mathrm{i}]+\mathrm{mu} \_2[\mathrm{j}]+\mathrm{mu} \_3[\mathrm{k}]+\mathrm{mu} \_12[\mathrm{i}, \mathrm{k}]\right)$

$+m_{-} 4[\mathrm{i}, \mathrm{j}, \mathrm{k}]=\exp \left(\mathrm{mu}+\mathrm{mu} \_1[\mathrm{i}]+\mathrm{mu} \_2[\mathrm{j}]+\mathrm{mu} \_3[\mathrm{k}]+\mathrm{mu} \_23[\mathrm{j}, \mathrm{k}]\right)$

$+\}$

$+\}$

$+\}$

$>$ m_1; m_2; m_3; m_4

,, 1

[,1] [,2] [,3]

[1,] 35.1822419 .6782021 .16897

[2,] 73.5628641 .1453344 .26240

, , 2

[,1] [,2] [,3]

[1,] 41.1707 23.02768 24.77220

[2,] 86.0842 48.1487951 .79642

, , 1

[,1] [,2] [,3]

[1,] 35.1822419 .6782021 .16897

[2,] 72.1882440 .3764743 .43529

, , 2

[,1] [,2] [,3]

[1,] 41.1707023 .0276824 .77220

[2,] 87.4588248 .9176552 .62353

, , 1

[,1] [,2] [,3]

[1,] 47.4607826 .5458628 .55691

[2,] 61.2843134 .2776736 .87446

,, 2

[,1] [,2] [,3]

[1,] 34.7058819 .4117620 .88235

[2,] 92.5490251 .7647155 .68627

, , 1

[,1] [,2] [,3]

[1,] 39.4705919 .4117617 .14706

[2,] 82.5294140 .5882435 .85294 
, , 2

[,1] [,2] [,3]

[1,] 36.8823523 .2941228 .79412

[2,] 77.1176548 .7058860 .20588

$>$ model1 $=\log \operatorname{lm}(\sim$ Chicksloss + Age + Breed, data $=n)$

$>$ model2 $=\log \operatorname{lm}(\sim$ Chicksloss + Age + Breed + Chicksloss*Breed, data $=n)$

$>$ model $3=\log \operatorname{lm}(\sim$ Chicksloss + Age + Breed + Chicksloss*Age, data $=n)$

$>$ model $4=\log \operatorname{lm}(\sim$ Chicksloss + Age + Breed + Age*Breed, data $=n)$

$>$ model1; model2; model3; model4

Call:

$\log \operatorname{lm}($ formula $=\sim$ Chicksloss + Age + Breed, data $=\mathrm{n})$

Statistics:

$$
\mathrm{X}^{\wedge} 2 \mathrm{df} \quad \mathrm{P}\left(>\mathrm{X}^{\wedge} 2\right)
$$

Likelihood Ratio $37.13769 \quad 74.41719 \mathrm{e}-06$

Pearson $\quad 36.33465 \quad 76.26767 \mathrm{e}-06$

Call:

$\log \operatorname{lm}($ formula $=\sim$ Chicksloss + Age + Breed + Chicksloss $*$ Breed, data $=n)$

Statistics:

$$
\mathrm{X}^{\wedge} 2 \mathrm{df} \quad \mathrm{P}\left(>\mathrm{X}^{\wedge} 2\right)
$$

Likelihood Ratio $36.81976 \quad 6$ 1.909229e-06

Pearson $\quad 35.20502 \quad 63.932731 \mathrm{e}-06$

Call:

$\log \operatorname{lm}($ formula $=\sim$ Chicksloss + Age + Breed + Chicksloss * Age, data $=n)$

Statistics:

$$
\mathrm{X}^{\wedge} 2 \mathrm{df} \quad \mathrm{P}\left(>\mathrm{X}^{\wedge} 2\right)
$$

Likelihood Ratio 8.280408 50.1414439

Pearson $\quad 8.181170 \quad 50.1465296$

Call:

$\log \operatorname{lm}($ formula $=\sim$ Chicksloss + Age + Breed + Age $*$ Breed, data $=\mathrm{n})$

Statistics:

$\mathrm{X}^{\wedge} 2 \mathrm{df} \quad \mathrm{P}\left(>\mathrm{X}^{\wedge} 2\right)$

Likelihood Ratio $29.68738 \quad 5$ 1.699225e-05

Pearson $\quad 28.75595 \quad 52.588877 \mathrm{e}-05$

$>\mathrm{m} \_5 \mathrm{a}=\mathrm{m} \_5 \mathrm{~b}=\mathrm{m} \_5 \mathrm{c}=\mathrm{m} \_6=\operatorname{array}(0, \operatorname{dim}=\mathrm{c}(\mathrm{I}, \mathrm{J}, \mathrm{K}))$

$>$ for(i in $1: I)\{$

+ for $(\mathrm{j}$ in $1: J)\{$

+ for $(\mathrm{k}$ in $1: \mathrm{K})\{$

$+\mathrm{m} \_5 \mathrm{a}[\mathrm{i}, \mathrm{j}, \mathrm{k}]=\exp \left(\mathrm{mu}+\mathrm{mu} \_1[\mathrm{i}]+\mathrm{mu} \_2[\mathrm{j}]+\mathrm{mu} \_3[\mathrm{k}]+\mathrm{mu} \_12[\mathrm{i}, \mathrm{j}]+\mathrm{mu} \_13[\mathrm{i}, \mathrm{k}]\right)$

$+\mathrm{m} \_5 \mathrm{~b}[\mathrm{i}, \mathrm{j}, \mathrm{k}]=\exp \left(\mathrm{mu}+\mathrm{mu} \_1[\mathrm{i}]+\mathrm{mu} \_2[\mathrm{j}]+\mathrm{mu} \_3[\mathrm{k}]+\mathrm{mu} \_12[\mathrm{i}, \mathrm{j}]+\mathrm{mu} \_23[\mathrm{j}, \mathrm{k}]\right)$

+ m_5c[i, j, k] $=\exp \left(m u+m u \_1[i]+m u \_2[j]+m u \_3[\mathrm{k}]+m u \_13[\mathrm{i}, \mathrm{k}]+\mathrm{mu} \_23[\mathrm{j}, \mathrm{k}]\right)$

$+m \_6[i, j, k]=\exp \left(m u+m u \_1[i]+m u \_2[j]+m u \_3[k]+m u \_12[i, j]+m u \_13[i, k]+m u \_23[j, k]\right)$

$+\}$

$+\}$

$+\}$

> m_5a; m_5b; m_5c; m_6

,, 1 
[,1] [,2] [,3]

[1,] 47.4607816 .5882411 .98039

[2,] 60.1391343 .4087052 .45217

, , 2

[,1] [,2] [,3]

[1,] 55.5392219 .4117614 .01961

[2,] 72.8608752 .5913063 .54783

,, 1

[,1] [,2] [,3]

[1,] 53.24576 16.36364 9.704225

[2,] 68.7542443 .6363643 .295775

, , 2

[,1] [,2] [,3]

[1,] 49.7542419 .6363616 .29577

[2,] 64.2457652 .3636472 .70423

,, 1

[,1] [,2] [,3]

[1,] 39.4705919 .4117617 .14706

[2,] 80.98723 39.8297935 .18298

, , 2

$[, 1] \quad[, 2] \quad[, 3]$

[1,] 36.88235 23.2941228 .79412

[2,] 78.34909 49.4836461 .16727

,, 1

[,1] [,2] [,3]

[1,] 53.24576 16.36364 9.704225

[2,] 67.4694742 .8209642 .486732

,, 2

$[, 1] \quad[, 2] \quad[, 3]$

[1,] 49.7542419 .6363616 .29577

[2,] 65.2716653 .1998073 .86519

$>$ model5a $=\log \operatorname{lm}(\sim$ Chicksloss + Age + Breed + Chicksloss*Age + Chicksloss *Breed, data $=n)$

$>$ model5b $=\log \operatorname{lm}(\sim$ Chicksloss + Age + Breed + Chicksloss*Age + Age*Breed, data $=\mathrm{n})$

$>$ model $5 \mathrm{c}=\log \mathrm{lm}(\sim$ Chicksloss + Age + Breed + Chicksloss* Breed + Age*Breed, data $=\mathrm{n})$

$>$ model $6=\log \operatorname{lm}(\sim$ Chicksloss + Age + Breed + Chicksloss*Age + Chicksloss $*$ Breed + Age*Breed , data $=\mathrm{n})$

$>$ model5a; model5b; model5c; model6

Call:

$\log \operatorname{lm}($ formula $=\sim$ Chicksloss + Age + Breed + Chicksloss * Age +

Chicksloss * Breed, data $=\mathrm{n}$ )

Statistics:

$$
\mathrm{X}^{\wedge} 2 \mathrm{df} \quad \mathrm{P}\left(>\mathrm{X}^{\wedge} 2\right)
$$




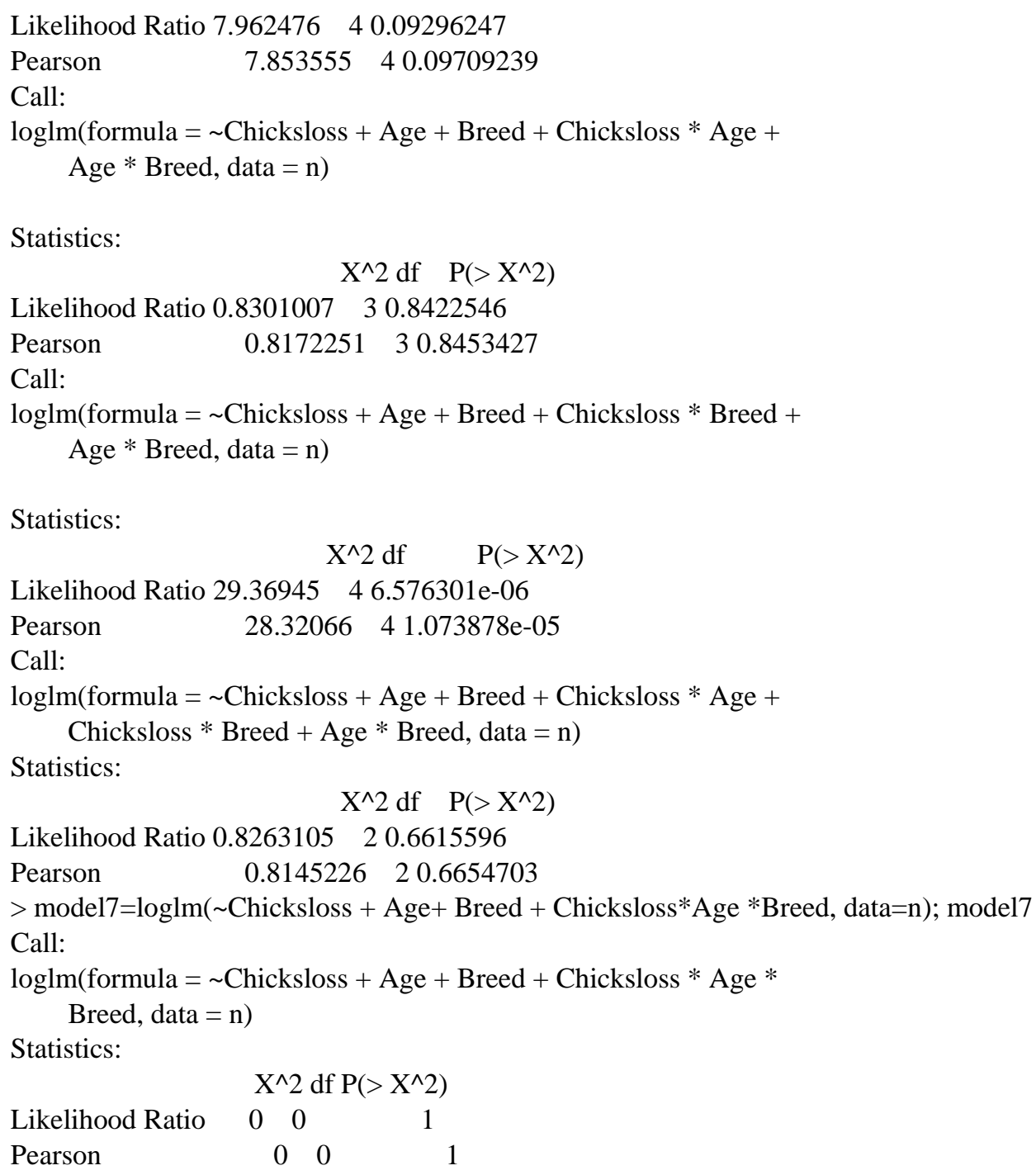

\section{Discussion}

The best model fit that explained the observed data is [CA, AB]. This model means that at significance level of $5 \%$, the data provide sufficient evidence (likelihood ratio $=0.83$, d.f $=2, \mathrm{P}=0.84$ or Pearson 0.82 , d.f $=2$, $\mathrm{P}=$ 0.84 ) that breed and chickloss are independent given the Age, thus the association or relationship between the breed and chickloss is independent for each age (Table 1 ).

The results of AIC and BIC confirmed that best model (CA, AB) adequately fit the data (Table 2).

\section{Conclusions}

A generalized method and algorithms developed for estimation of the parameters and best model fits of log linear model for $n$-dimensional contingency table. Three-dimensional contingency table was considered for this paper. In estimating these parameter estimates and best model fits, computer programs in R were developed for the implementation of the algorithms. The iterative proportional fitting procedure was used to estimate the parameter estimates and goodness of fits of the log linear model.

The results of the analysis showed that the best model fit for 3-dimensional contingency table was [CA, AB]. This shows that the best model fit has sufficient evidence to fit the data without loss of information. This model also revealed that breed was independent of chick loss given age. It also discovered that the results of the goodness of fit showed that the best model adequately fit the data having the highest P-value and least likelihood ratio 
Table 1. Summary of the results of goodness of fit.

\begin{tabular}{ccccc}
\hline Models & $G^{2}$ & $\chi^{2}$ & d.f & P-value \\
\hline [C, A, B] & 37.14 & 36.34 & 7 & 0 \\
{$[\mathrm{~A}, \mathrm{CB}]$} & 36.82 & 35.21 & 6 & 0 \\
{$[\mathrm{~B}, \mathrm{CA}]$} & 8.28 & 8.18 & 5 & 0.14 \\
{$[\mathrm{C}, \mathrm{AB}]$} & 29.69 & 28.76 & 5 & 0.093 \\
{$[\mathrm{CA}, \mathrm{CB}]$} & 7.96 & 7.85 & 4 & 0.84 \\
{$[\mathrm{CA}, \mathrm{AB}]$} & 0.83 & 0.82 & 3 & 0 \\
{$[\mathrm{CB}, \mathrm{AB}]$} & 29.36 & 28.32 & 4 & 0.66 \\
{$[\mathrm{CA}, \mathrm{CB}, \mathrm{AB}]$} & 0.83 & 0.81 & 2 & 0 \\
{$[\mathrm{CAB}]$} & 0 & 0 & & 0 \\
\hline
\end{tabular}

P-value for $G^{2}$.

Table 2. Summary of the results of the test statistics used for checking the adequacy of the best model fit (AIC, BIC, $G^{2}$ and $\left.\chi^{2}\right)$.

\begin{tabular}{ccccccc}
\hline Model & AIC & BIC & $G^{2}$ & $\chi^{2}$ & d.f & P-value \\
\hline (C, A, B) & 24.14 & -6.50 & 37.14 & 36.33 & 7 & $<0.001$ \\
$(\mathrm{C}, \mathrm{AB})$ & 19.69 & -1.48 & 29.69 & 28.76 & 5 & $<0.001$ \\
$(\mathrm{~A}, \mathrm{CB})$ & 24.82 & -0.59 & 36.82 & 35.21 & 6 & $<0.001$ \\
$(\mathrm{CB}, \mathrm{AB})$ & 21.37 & 4.43 & 29.37 & 28.32 & 4 & $<0.001$ \\
$(\mathrm{CA}, \mathrm{AB})$ & -5.17 & -17.87 & 0.83 & 0.82 & 3 & 0.84 \\
$(\mathrm{CA}, \mathrm{CB})$ & -0.04 & -16.98 & 7.96 & 7.85 & 4 & 0.09 \\
$(\mathrm{CA}, \mathrm{CB}, \mathrm{AB})$ & -3.17 & 11.64 & 0.83 & 0.82 & 2 & 0.67 \\
$(\mathrm{CAB})$ & 0 & 0 & 0.00 & 0.00 & 0 & $\mathrm{I}$ \\
\hline
\end{tabular}

estimate. The values of the best of fit statistics are: likelihood ratio $\left(G^{2}\right)=0.83$, d.f $=3$, and P-value $=0.84$; Pearson chi-square $\left(\chi^{2}\right)=0.82$, d.f $=3$, and P-value $=0.84$. The results of AIC and BIC confirmed the best model adequacy to the data. The final model in harmony with the hierarchy principle is written as:

$\operatorname{Logm}_{i j k}=\mu+\mu_{C(i)}+\mu_{A(j)}+\mu_{B(k)}+\mu_{C A(i j)}+\mu_{A B(j k)}$.

\section{References}

[1] Agresti, A. (2002) Categorical Data Analysis. 2nd Edition, John Wiley \& Sons, Inc., New York, 320-332. http://dx.doi.org/10.1002/0471249688

[2] Knoke, D. and Burke, P.J. (1980) Log-Linear Models. Sage Publications, Inc., New Jersey, 8-17.

[3] Akaike, H. (1987) Factor Analysis and AIC. Psychometrika, 52, 317-332. http://dx.doi.org/10.1007/BF02294359

[4] Anderson, A.H. (1974) Multidimensional Contingency Tables. Scandinavean Journal of Statistics, 1, 115-127.

[5] Green, J.A. (1988) Bayesian Model Comparison for the Order Restricted RC Association Model. Psychometrica, 74, 561-587.

[6] Marascuilo, L. (1987) Log Linear Models: A Way to Study Main Effects and Interactions for Multidimensional with Categorical Data. Journal of America Psychological Associations, 34, 443-445.

[7] Onder, M. and Adiguzel, E. (2010) Evaluation of Occupational Facilities among Underground Coal Mine Workers through Log-Linear Models. Industrial Health, 48, 872-878. http://dx.doi.org/10.2486/indhealth.MS1136

[8] Olmus, H. (2012) Analysis of Traffic Accidents Caused by Drivers Using Log-Linear Models. Promet-Traffic \& 
Transportation, 24, 495-504.

[9] Shaffer, J.P. (1973) Defining and Testing Hypothesis in Three-Dimensional Contingency Tables. Psychological Bulletin, 79, 127-141. http://dx.doi.org/10.1037/h0033865

[10] Deming, W.E. and Stephen, F.F. (1940) On Least Square Adjustment of a Frequency Tables When the Expected Marginal Totals Are Known. Annals of Mathematical Statistics, 11, 427-444. http://dx.doi.org/10.1214/aoms/1177731829

[11] Pearson, K. (1990) On a Criterion That a Given System of Derivations from Probable in the Case of a Corrected System of Variables Is Such That It Can Be Reasonably Supposed to Have Arisen from a Random Sampling. Philosophical Magazine, 50, 157-175. http://dx.doi.org/10.1080/14786440009463897

[12] Wilks, S.S. (1938) The Large Distribution of the Likelihood Ratio for Testing Composite Hypotheses. Annals of Mathematical Statistics, 9, 60-62. http://dx.doi.org/10.1214/aoms/1177732360

[13] Kullback, S. (1959) Information Theory and Statistics. Wiley, New York.

[14] Neyman, J. (1949) Contribution to the Theory of Chi-Square Test. Proceedings of the First Berkeley Symposium on Mathematical Statistics and Probability, 239-273.

[15] Bishop, Y.M.M., et al. (1975) Discrete Multivariate Analysis: Theory and Practice. Mass MIT Press, Cambridge, 1837.

[16] Lawal, H.B. (2003) Categorical Data Analysis with SAS and SPSS Applications. Lawrence Erlbaum Associates, Inc., New Jersey, 83-128.

[17] Raftery, A.E. (1986) A Note on Bayesian Factors for Log-Linear Contingency Table Models with Vague Prior Information. Journal of the Royal Statistical Society, Series B, 48, 249-250. 